\title{
PET of $(R)-{ }^{11}$ C-Rolipram Binding to Phosphodiesterase-4 Is Reproducible and Sensitive to Increased Norepinephrine in the Rat Heart
}

\author{
Adam J. Thomas ${ }^{1,2}$, Jean N. DaSilva ${ }^{1,2}$, Mireille Lortie ${ }^{1}$, Jennifer M. Renaud ${ }^{1}$, Miran Kenk ${ }^{1,2}$, Rob S. Beanlands ${ }^{1,2}$, \\ and Robert A. deKemp ${ }^{1}$ \\ ${ }^{1}$ Cardiovascular PET Molecular Function and Imaging Program, National Cardiac PET Centre, Division of Cardiology, University of \\ Ottawa Heart Institute, Ottawa, Ontario, Canada; and ${ }^{2}$ Department of Cellular and Molecular Medicine, Faculty of Medicine, \\ University of Ottawa, Ottawa, Ontario, Canada
}

Phosphodiesterase-4 (PDE4) plays a critical role in the regulation of $\beta$-adrenergic receptor-stimulated cyclic adenosine monophosphate cell signaling in the heart. $(R)$-rolipram, a PDE4-selective inhibitor, has been studied previously as a radiotracer for the quantification of PDE4 levels. The aim of this study was to characterize $(R)-{ }^{11} \mathrm{C}$-rolipram binding in the rat myocardium in vivo, using small-animal PET. Methods: Male Sprague-Dawley rats $(n=30)$ were administered $(R)-{ }^{11} \mathrm{C}$-rolipram and imaged for $60 \mathrm{~min}$ to evaluate tracer binding and reproducibility, quantified using Logan slope analysis of the distribution volume. Dynamic ${ }^{13} \mathrm{~N}$-ammonia imaging was performed to quantify myocardial blood flow and assist in cardiac regional analysis. Saturation studies evaluated the sensitivity of $(R)-{ }^{11} \mathrm{C}$-rolipram to PDE4 blocking by unlabeled cold $(R)$ rolipram $(0.0001-1.0 \mathrm{mg} / \mathrm{kg})$, for estimation of the median effective dose $\left(\mathrm{ED}_{50}\right)$ in the heart. $(R)-{ }^{11} \mathrm{C}$-rolipram response to enhanced norepinephrine stimulation of the $\beta$-adrenergic receptor with desipramine (20 mg/kg, intravenous) was also studied. Intrarat variability studies $(n=5)$ were conducted with test-retest imaging at $16 \pm 7 \mathrm{~d}$. Results: A reduction of Logan slope was observed with increasing cold mass coadministered with the tracer, with an $\mathrm{ED}_{50}$ of $0.0019 \mathrm{mg} / \mathrm{kg}$ (95\% confidence interval, 0.0014-0.0052) estimated from the saturation studies. This $\mathrm{ED}_{50}$ predicted less than $10 \%$ enzyme occupancy at $0.0002 \mathrm{mg}$ of cold $(R)$-rolipram per kilogram (mass/body weight). Low-occupancy imaging at $0.00018 \pm 0.00002 \mathrm{mg} / \mathrm{kg}$ produced a mean Logan slope of $5.5 \pm 0.85 \mathrm{~mL} / \mathrm{cm}^{3}$. Enzyme saturation of more than $90 \%$, compared with low-occupancy conditions, occurred at more than $0.02 \mathrm{mg} / \mathrm{kg}$, with a complete blocking dose ( $>1 \mathrm{mg}$ of $(R)$-rolipram per kilogram) resulting in a Logan slope of $3.3 \pm 0.1 \mathrm{~mL} / \mathrm{cm}^{3}$, representing a $40 \%$ reduction. Compared with baseline, a Logan slope of $6.8 \pm 0.7 \mathrm{~mL} / \mathrm{cm}^{3}$ in desipramine-challenged animals was observed, representing a $30 \%$ increase due to acute norepinephrine stimulation, despite a reduction in myocardial blood flow. Intrarat and intraoperator variability was less than $5 \%$ between repeated measures. Conclusion: $(R)-{ }^{11} \mathrm{C}$-rolipram shows the ability to

Received Aug. 26, 2010; revision accepted Nov. 3, 2010.

For correspondence or reprints contact: Robert A. deKemp, National Cardiac PET Centre, University of Ottawa Heart Institute, 40 Ruskin St., Ottawa, Ontario, Canada, K1Y 4W7.

E-mail: RAdeKemp@ottawaheart.ca

COPYRIGHT @ 2011 by the Society of Nuclear Medicine, Inc. monitor increases and decreases in PDE4 availability in the rat myocardium, with good reproducibility.

Key Words: (R)-rolipram; PDE4; desipramine; test-retest repeatability

J Nucl Med 2011; 52:263-269

DOI: 10.2967/jnumed.110.082701

$\mathbf{P}$ hosphodiesterase (PDE) enzymes are responsible for the hydrolysis of secondary messengers cyclic adenosine monophosphate (cAMP) and cyclic guanosine monophosphate to their inactive $5^{\prime}$ forms, terminating intracellular signaling. In the heart, the primary phosphodiesterase isozymes are phosphodiesterase- 3 and phosphodiesterase-4 (PDE4) (1). Importantly, PDE4 is regulated by cAMP levels through downstream effectors, increasing PDE4 activity in acutely altered signaling states and increasing PDE4 expression with chronically altered states (1).

Rolipram $((R / S)$-4-(3-cyclopentyloxy-4-methoxyphenyl2-pyrrolidone), a PDE4-selective inhibitor (2), has been labeled with ${ }^{11} \mathrm{C} \mathrm{(3)}$ and applied as a radiotracer for in vivo imaging with PET in rat (4-7), pig (8), and human (9) studies. Quantifying tissue distribution of ${ }^{11} \mathrm{C}$-labeled $(R)$ rolipram may provide an in vivo measure of PDE4 levels as an indirect measure of cAMP intracellular signaling.

Our previous in vitro work demonstrated specific and selective PDE4 binding in the rat heart (10-12). Thus, the aim of the present study was to characterize the in vivo binding specificity, responsiveness to acute norepinephrine treatment, and reproducibility of $(R)-{ }^{11} \mathrm{C}$-rolipram imaging in the rat myocardium with small-animal PET.

\section{MATERIALS AND METHODS}

\section{Animals}

Male Sprague-Dawley rats $(n=30)$ weighing $225-515 \mathrm{~g}$ were maintained on a 12-h light-dark cycle with water and food ad libitum. All experiments were conducted with approval from the Animal Care Committee at the University of Ottawa. 


\section{Radiotracer Synthesis}

$(R)-{ }^{11} \mathrm{C}$-rolipram $(7.4-315 \mathrm{GBq} / \mu \mathrm{mol})$ was synthesized as described previously (3) or in higher specific activity using a recirculation gas-phase system from ${ }^{11} \mathrm{C}$-methane and iodine (13) in high radiochemical purity $(>95 \%) .{ }^{13} \mathrm{~N}$-ammonia was obtained from routine clinical synthesis. Unlabeled $(R)$-rolipram (Ascent Scientific) was dissolved in ethanol:propylene-glycol:0.9\% saline (5:20:75, v/v/v). Desipramine hydrochloride (Sigma-Aldrich) was dissolved in $0.9 \%$ saline.

\section{Arterial Input Function Corrections}

Plasma-to-Whole-Blood Ratio. Activity in whole blood and plasma was measured at serial time points to determine the proportion in plasma to whole blood. Rats $(n=9)$ were treated with buprenorphine analgesic $(0.04 \mathrm{mg} / \mathrm{kg}$, intraperitoneally) and anesthetized with $1 \%-2 \%$ isoflurane. The carotid artery was cannulated for serial blood collection. $(R)-{ }^{11} \mathrm{C}$-rolipram (11.185.5 MBq) was injected via the tail vein, and arterial blood $(150-300 \mu \mathrm{L})$ was collected at $0.5,1,5,20,30,45$, and $60 \mathrm{~min}$. Blood samples were weighed and counted for activity (Cobra II $\gamma$-Counter; Packard). Samples were centrifuged for $5 \mathrm{~min}$ at $4,000 \mathrm{~g}$, and the supernatant was collected, weighed, and counted to determine the plasma activity per gram.

${ }^{11}$ C-Labeled Metabolites in Plasma. Studies were performed to determine the proportions of unchanged $(R)^{-11} \mathrm{C}$-rolipram and ${ }^{11} \mathrm{C}$-labeled metabolites in plasma. Rats received a 300- to 370MBq dose of $(R)-{ }^{11} \mathrm{C}$-rolipram and were sacrificed at 5, 15, and $60 \min (n=3$ for each) for collection of trunk blood. Blood samples were centrifuged for $5 \mathrm{~min}$ at $4,000 \mathrm{~g}$, and plasma was collected and double-filtered $(0.22 \mu \mathrm{m})$ to remove excess plasma proteins for analysis with our high-performance liquid chromatography column-switch method (12). Previous data (12) were used to complete the plasma metabolite time course at 30 and $45 \mathrm{~min}$.

\section{PET}

Animals were anesthetized with $1 \%-2 \%$ isoflurane, with heart rate, respiratory rate, and temperature monitored during imaging with a Siemens Inveon scanner. A 30-min dynamic ${ }^{13} \mathrm{~N}$-ammonia scan $(52-126 \mathrm{MBq})$ was obtained to quantify myocardial blood flow (MBF) and assist with region-of-interest placement in coregistered $(R)-{ }^{11} \mathrm{C}$-rolipram images. Thirty minutes later, a $60-\min (R)-{ }^{11} \mathrm{C}-$ rolipram (7.4-92.5 MBq) dynamic scan $(9 \times 10 \mathrm{~s}, 3 \times 30 \mathrm{~s}, 2 \times 60 \mathrm{~s}$, and $5 \times 300 \mathrm{~s}$ ) was acquired. A $10-\mathrm{min}{ }^{57} \mathrm{Co}$ transmission scan was acquired for attenuation correction. PET images $\left(\mathrm{Bq} / \mathrm{cm}^{3}\right)$ were reconstructed using the vendor-provided 3-dimensional orderedsubset expectation maximization maximum a posteriori algorithm $(\beta=1)$, with all corrections enabled.

\section{PET Image Analysis}

FlowQuant (uOHI) software was used to generate time-activity curves of tracer concentration in arterial blood and polar maps of tracer uptake and clearance in the left-ventricular myocardium. Quantitative MBF values $(\mathrm{mL} / \mathrm{min} / \mathrm{g})$ were derived from ${ }^{13} \mathrm{~N}$ ammonia curves using a 1-tissue-compartment model (14).

Logan slopes $\left(\mathrm{mL} / \mathrm{cm}^{3}\right)$ were derived graphically from the $(R)-{ }^{11} \mathrm{C}$-rolipram curves at $20-60 \mathrm{~min}$ after injection, using a partial-volume recovery coefficient of 0.6. The Logan slope is a function of free receptor or enzyme concentration, providing an index of in vivo binding potential for reversibly bound tracers (15). Some labeled metabolites are present in rat cardiac tissue, although these do not bind specifically to PDE4 (12). Therefore, a component of the Logan slope can represent labeled metabolites; however, the method still provides a useful index of tracer binding potential in lieu of full compartmental modeling. ${ }^{11} \mathrm{C}$-rolipram image analysis was repeated twice to assess operator variability. Intraoperator variability was evaluated using 2 measurements obtained by operator A. Interoperator variability was assessed by comparing values between operator $\mathrm{A}$ and a second operator $\mathrm{B}$.

\section{PDE4 Enzyme Saturation Studies}

To determine the effect of an injected mass $(0.0001-1.0 \mathrm{mg} / \mathrm{kg})$ of unlabeled cold compound on $(R)-{ }^{11} \mathrm{C}$-rolipram binding, studies were conducted to estimate a median effective dose $\left(\mathrm{ED}_{50}\right)$ in the rat heart.

Full PDE4 blockade studies $(n=3)$ were conducted in rats preinjected with a saturating dose of $(R)$-rolipram $(1 \mathrm{mg} / \mathrm{kg}$, intravenously) (11) to establish the nondisplaceable proportion of binding. In the range of $0.003-0.35 \mathrm{mg} / \mathrm{kg}$, rats $(n=5)$ received $(R)-{ }^{11} \mathrm{C}$-rolipram coinjected with added unlabeled $(R)$-rolipram. Below $0.03 \mathrm{mg} / \mathrm{kg}(n=22)$, the unlabeled component of the tracer formulation was calculated from the specific activity; radiochemistry limitations permitted an injection of $0.00016 \mathrm{mg} / \mathrm{kg}$ as the lowest mass dose. PET camera sensitivity also prevented the injection of lower masses while still maintaining activity above 7.4 MBq.

The $\mathrm{ED}_{50}$ for myocardial $(R)$-rolipram binding was estimated by fitting the following function to all $(n=30)$ Logan slope values:

$$
\text { Logan slope }=\left[\mathrm{V}_{\mathrm{S}} /\left(1+\mathrm{IM} / \mathrm{ED}_{50}\right)\right]+\mathrm{V}_{\mathrm{ND}}, \quad \text { Eq. } 1
$$

where IM is the injected mass dose, $V_{S}$ is the specific binding distribution volume, and $\mathrm{V}_{\mathrm{ND}}$ is the nondisplaceable distribution volume of the tracer (16). Using these data, we established a low receptor occupancy $(<10 \%)$ target to perform the following studies.

\section{Response to Acute Norepinephrine Elevation}

Rats $(n=5)$ were imaged with $(R)-{ }^{11} \mathrm{C}$-rolipram first at baseline and then $2-7 \mathrm{~d}$ later with acute desipramine challenge $(20 \mathrm{mg} / \mathrm{kg}$, intraperitoneally, at $3 \mathrm{~h}$ before tracer administration). Because desipramine can cause depressed hemodynamics at high doses (17), ${ }^{13} \mathrm{~N}$-ammonia MBF was used to evaluate potential changes in the tracer delivery of $(R)-{ }^{11} \mathrm{C}$-rolipram.

\section{(R)- ${ }^{11}$ C-Rolipram Reproducibility Studies}

Interrat variability was assessed at low-occupancy conditions $(<10 \% ; 0.00018 \pm 0.00002 \mathrm{mg} / \mathrm{kg})$ in 13 animals. The intrarat variability was assessed using test-retest imaging $(n=5)$ within $16.4 \pm 6.7 \mathrm{~d}$ to yield repeated measures.

\section{Mathematic and Statistical Analysis}

Curve fitting was performed using MATLAB (The MathWorks). Student $t$ tests were completed using SPSS software (SPSS Inc.), and a $P$ value less than 0.05 was considered statistically significant.

\section{RESULTS}

\section{Arterial Input Function Corrections}

Plasma-to-Whole-Blood Ratio. Plasma-to-whole-blood ratios varied from 0.8 initially to 1.2 at $0-60 \mathrm{~min}$ (Fig. 1). The following equation was fit to the ratio data $\left(r^{2}=0.98\right)$ :

$$
\mathrm{F}(\mathrm{t})=1.15-0.24 \mathrm{e}^{-0.02 \mathrm{t}}, \quad \text { Eq. } 2
$$

providing a whole-blood correction for radioactivity in plasma over time. 


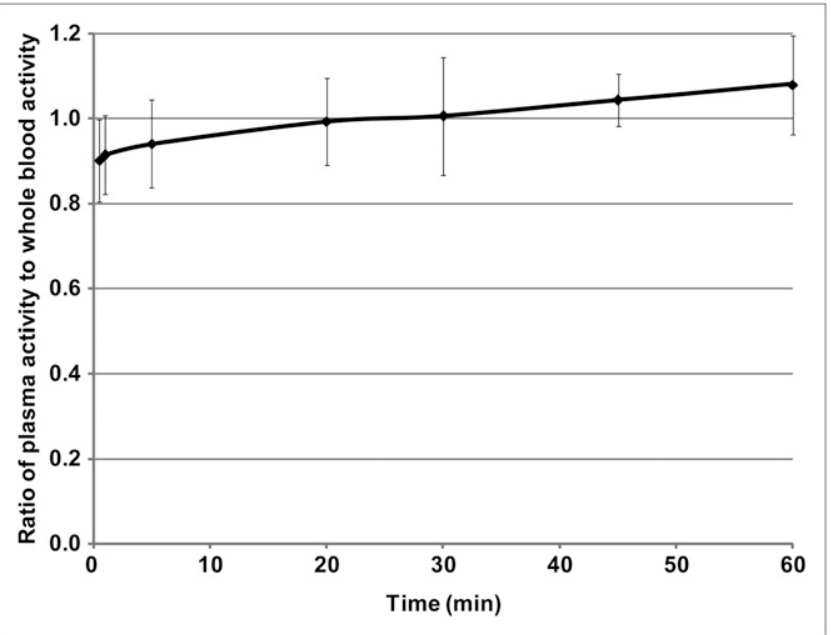

FIGURE 1. Ratio of plasma-to-whole-blood activity over time (min) in rat for $(R)-{ }^{11} \mathrm{C}$-rolipram as measured by carotid artery blood sampling (150-300 $\mu \mathrm{L})$. Data are presented as mean $\pm \mathrm{SD}(n=3$ at each data point). Fitted whole-blood-to-plasma correction function is $F(t)=1.15-0.24 e^{-0.02 t}$.

${ }^{11} \mathrm{C}$-Labeled Metabolites in Plasma. $(R)-{ }^{11} \mathrm{C}$-rolipram was rapidly metabolized. At $15 \mathrm{~min}, 27 \%$ of radioactivity in plasma was associated with the unaltered parent compound, whereas the remaining activity derived from labeled metabolites (Fig. 2). The following equation was fit to the metabolite data $\left(r^{2}=0.95\right)$ :

$$
F(t)=0.7 e^{-0.23 t}+0.3 e^{-0.007 t},
$$

providing a metabolite correction for unaltered parent tracer in plasma.

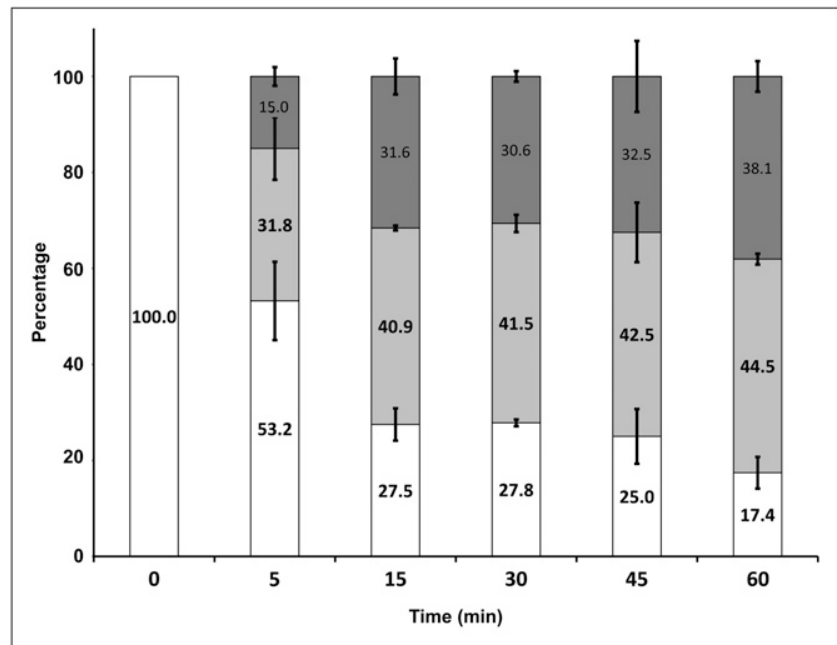

FIGURE 2. Proportion of plasma activity associated with hydrophilic metabolites eluted from capture column (light shaded bars), hydrophilic metabolites eluted with solvent front (dark shaded bars), and unchanged parent tracer (white bars) at various time points (min). Derived plasma metabolite correction function is $F(t)=0.7$ $\mathrm{e}^{-0.23 \mathrm{t}}+0.3 \mathrm{e}^{-0.007 t}$. Error bars represent $\pm S D$.

\section{PET}

The $(R)-{ }^{11} \mathrm{C}$-rolipram small-animal PET images consistently show high uptake in the heart (Fig. 3) and liver (Fig. 4 ). The myocardium-to-blood ratio was $1.4 \pm 0.23$ averaged across all imaging conditions.

\section{PDE4 Enzyme Occupancy Studies}

The $\mathrm{ED}_{50}$, estimated using Equation 1, was $0.0019 \mathrm{mg} / \mathrm{kg}$ (95\% confidence interval, 0.0014-0.0052; $r^{2}=0.63$ ) (Fig. 5 ), and the specific binding was $2 \mathrm{~mL} / \mathrm{cm}^{3}$.

Assuming this $\mathrm{ED}_{50}$, less than $10 \%$ occupancy would occur at $0.0002 \mathrm{mg} / \mathrm{kg}$. In the low-occupancy studies $(n=$ $13 ; 0.00018 \pm 0.00002 \mathrm{mg} / \mathrm{kg}$ ), the Logan slope was $5.5 \pm$ $0.85 \mathrm{~mL} / \mathrm{cm}^{3}$ (Table 1).

Images $(>1 \mathrm{mg} / \mathrm{kg},(R)$-rolipram) in the PDE4-blocking animals, as compared with the low-occupancy rats (1.6 \pm 0.22 ), were characterized by a low myocardium-to-blood ratio $(1.1 \pm 0.06)(P<0.05$; Fig. 4$)$. A mean Logan slope of $3.3 \pm 0.1 \mathrm{~mL} / \mathrm{cm}^{3}$ (Table 1 ) in these animals, compared with low-occupancy conditions, represented a significant $40 \%$ reduction $(P<0.01)$.

\section{Response to Acute Norepinephrine Elevation}

Acute desipramine challenge resulted in Logan slopes of $6.8 \pm 0.70 \mathrm{~mL} / \mathrm{cm}^{3}$ (Table 1 ). These same rats had baseline Logan slopes of $5.2 \pm 0.77 \mathrm{~mL} / \mathrm{cm}^{3}$, representing a signifi-
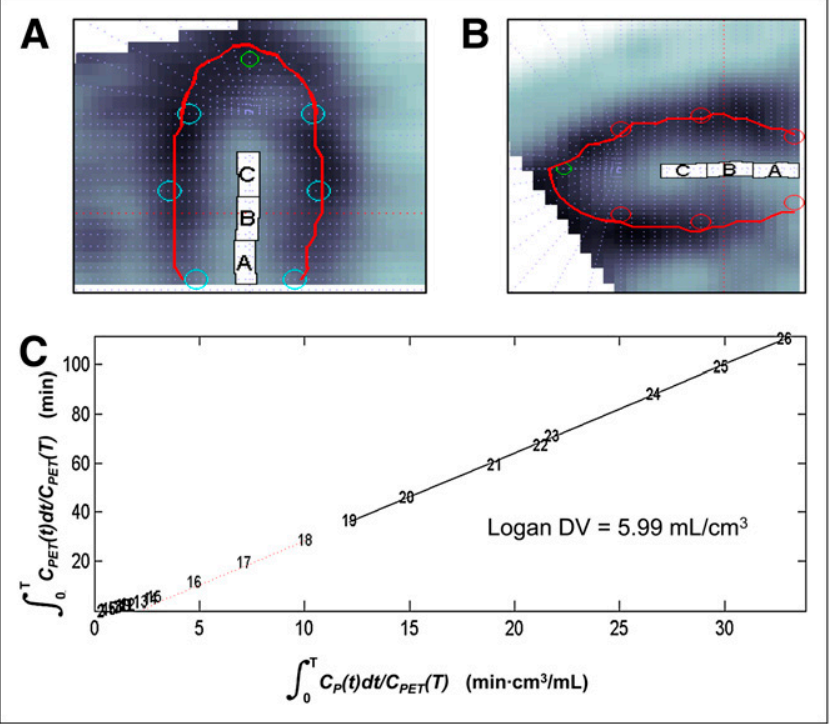

FIGURE 3. Reconstructed $(R)-{ }^{11} \mathrm{C}$-rolipram images showing high tracer uptake in rat heart (frame 15, 4-5 min after tracer administration; $17 \mathrm{MBq}$ injected activity, $0.04 \mu \mathrm{g}$ injected mass [0.00016 $\mathrm{mg} / \mathrm{kg}]$ ). Myocardial (red) regions of interest placed using horizontallong-axis (A) and vertical-long-axis (B) orientations with wholeblood regions taken at locations $A, B$, and $C$, representing left atrium, base, and cavity of heart, respectively. Representative Logan slope graphic analysis plot (C) showing linear relationship from 20 to $60 \mathrm{~min}$ (frames 19-26). In axis labels, $C_{P}(t)=$ concentration of parent $(R)-{ }^{11} \mathrm{C}$-rolipram in plasma and $\mathrm{C}_{\mathrm{PET}}(\mathrm{t})=$ concentration of $(R)-{ }^{11} \mathrm{C}$-rolipram in tissue after correction for blood volume and partial-volume loss. 

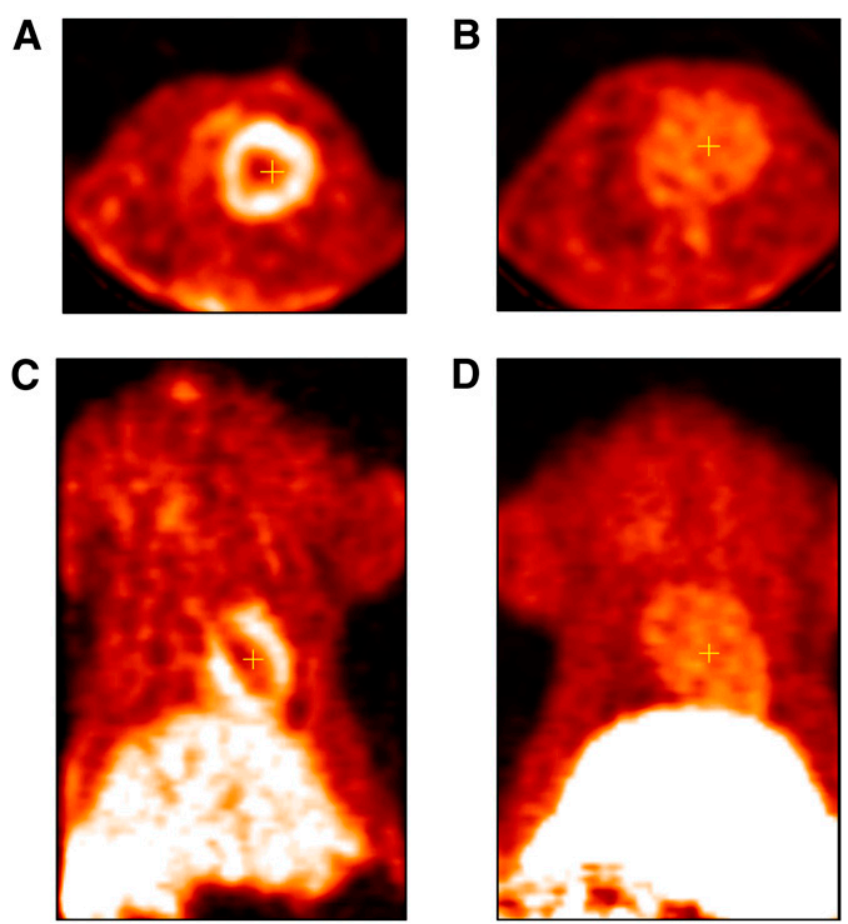

FIGURE 4. Reconstructed $(R)-{ }^{11} \mathrm{C}$-rolipram transverse and coronal images in rats comparing cardiac signal in representative baseline image (A and C) (frame 15, 4-5 min after tracer administration; $17 \mathrm{MBq}$ of injected activity, $0.04 \mu \mathrm{g}$ injected mass [0.00016 mg/kg]) vs. complete blocking image (B and $D$ ) with $1 \mathrm{mg}$ of $(R)$-rolipram per kilogram injected at 2-5 min before $(R)-{ }^{11} \mathrm{C}$-rolipram (frame 15 , 4-5 min after tracer administration; $81 \mathrm{MBq}$ of injected activity, $0.89 \mu \mathrm{g}$ injected mass [1.003 mg/kg]).

cant $30 \%$ increase $(P<0.01$, Fig. 6) and a significant $24 \%$ increase, compared with low-occupancy conditions $(P<0.01)$.

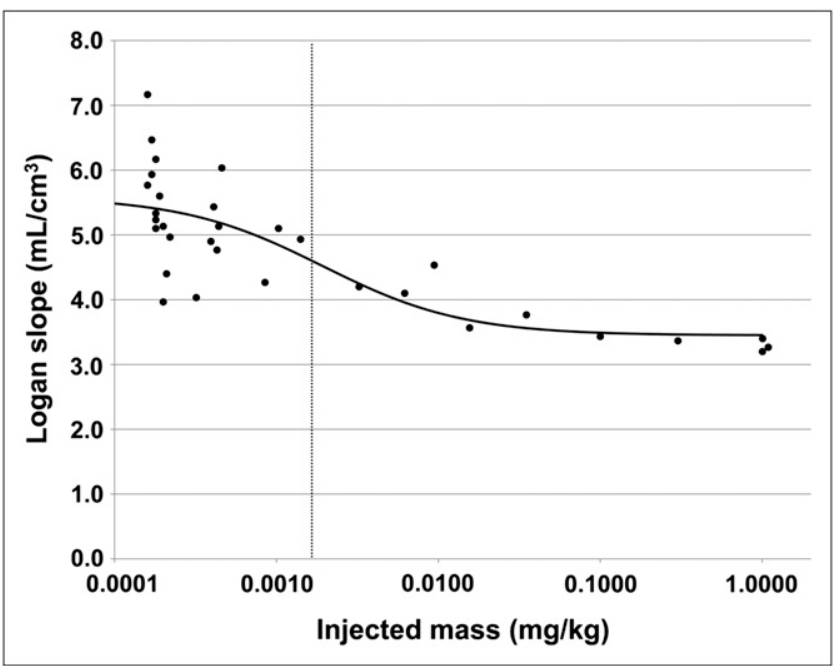

FIGURE 5. Dose-response curve for injected mass of $(R)-{ }^{11} \mathrm{C}$-rolipram vs. Logan slope over injected mass range of 0.00016-1.09 $\mathrm{mg} / \mathrm{kg}$. An $\mathrm{ED}_{50}$ of $0.0019 \mathrm{mg} / \mathrm{kg}$ (95\% confidence interval of $0.0014-0.0052$, dashed vertical line) was estimated by fitting the following equation to the data: $L S=\left[V_{S} /\left(1+I M / E D_{50}\right)\right]+V_{N D}$. $\mathrm{IM}=$ injected mass; $\mathrm{LS}=$ Logan slope; $\mathrm{V}_{\mathrm{ND}}=$ nondisplaceable distribution volume; $V_{S}=$ specific binding distribution volume.
TABLE 1

Quantitative $(R)-{ }^{11} \mathrm{C}-$ Rolipram Logan Slope and ${ }^{13} \mathrm{~N}-A m m o n i a$ MBF Values for Baseline, Blocked, and Desipramine Challenge Groups

\begin{tabular}{lcc}
\hline \multicolumn{1}{c}{ Group } & $\begin{array}{c}\text { Logan slope } \\
( \pm \mathrm{SD})\end{array}$ & $\mathrm{MBF}( \pm \mathrm{SD})$ \\
\hline $\begin{array}{c}\text { Baseline, low occupancy } \\
(0.00018 \mathrm{mg} / \mathrm{kg})\end{array}$ & $5.5( \pm 0.85)$ & $3.5( \pm 0.60)$ \\
$\begin{array}{c}\text { Blocked, total PDE4 } \\
\text { saturation }(>1.0 \mathrm{mg} / \mathrm{kg})\end{array}$ & $3.3^{\star}( \pm 0.10)$ & $3.9( \pm 0.61)$ \\
$\begin{array}{l}\text { Desipramine challenge } \\
(0.00018 \mathrm{mg} / \mathrm{kg})\end{array}$ & $3.0( \pm 0.55)$ \\
& & \\
\hline & & \\
${ }^{\star} P<0.01$ blocked vs. baseline. \\
${ }^{\dagger} P<0.001$ desipramine vs. baseline. \\
${ }^{\ddagger} P<0.001$ desipramine vs. blocked.
\end{tabular}

Parallel MBF measurements in these rats revealed a significant $23 \%$ reduction in flow with desipramine versus untreated rats $(P<0.001$, Fig. 6). In absolute terms, MBF dropped from 3.9 to $3.0 \mathrm{~mL} / \mathrm{min} / \mathrm{g}$ at $3 \mathrm{~h}$ after desipramine administration. Therefore, the increased $(R)-{ }^{11} \mathrm{C}$-rolipram binding observed with desipramine cannot be attributed to changes in tracer delivery.

\section{(R)-11C-Rolipram Reproducibility Studies}

Logan slope values at less than $10 \%$ occupancy ranged from 4.0 to 7.2 , with a mean of $5.5 \pm 0.85 \mathrm{~mL} / \mathrm{cm}^{3}$ in 13 studies (Table 1), representing a $15 \%$ coefficient of variation between rats.

Test-retest studies revealed small variability within rats; the difference between repeated measures ranged from $1.9 \%$ to $8.6 \%$, with a mean of $4.6 \% \pm 2.8 \%$. Bland-Altman analysis showed a small $5 \%$ bias toward higher values in the second study relative to the first $(P<0.05$, Fig. 7).

Operator variability studies showed that the interoperator difference in Logan slope values was $4.7 \% \pm 2.8 \%$, whereas intraoperator values differed by $4.4 \% \pm 4.3 \%$ on average and always by less than $13 \%$.

\section{DISCUSSION}

PDE enzymes, through their ability to hydrolyze cyclic nucleotides, play a critical role in limiting and attenuating cell signaling. cAMP-specific PDE4 is of particular functional importance because it hydrolyzes most cAMP produced in rats (1). Further, cAMP levels act to regulate PDE4 expression and activity through negative-feedback mechanisms (1). Given this relationship between PDE4 and cAMP, PDE4-specific $(R)-{ }^{11} \mathrm{C}$-rolipram distribution volume is reflective of the cardiac signaling environment, and using this radioligand with small-animal PET can provide an in vivo window to monitor this intracellular signaling cascade. The in vivo characterization of $(R)-{ }^{11} \mathrm{C}$-rolipram small-animal PET reported here demonstrates qualitative and quantitative features favorable for cardiac imaging in rats. 


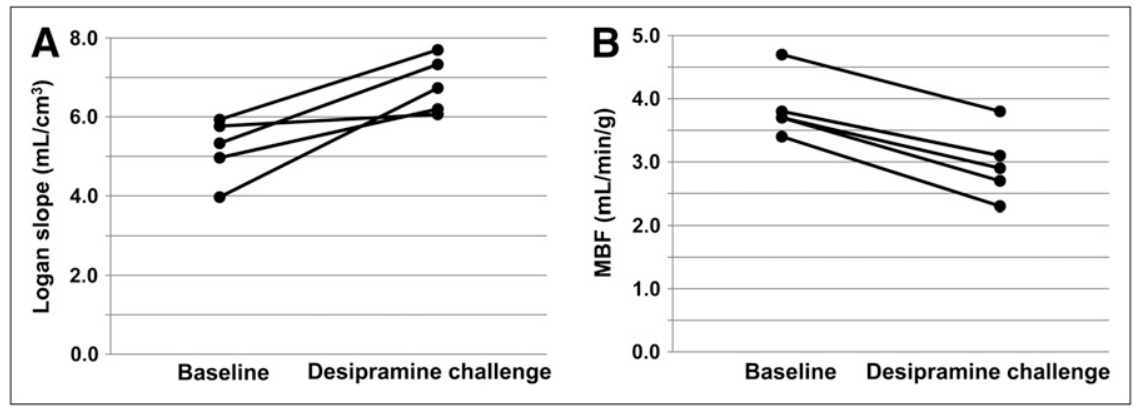

FIGURE 6. Baseline vs. desipramine challenge $(20 \mathrm{mg} / \mathrm{kg}, 3 \mathrm{~h}$ before tracer administration, intraperitoneally) studies. (A) Increased Logan slope values after desipramine challenge $(P<0.01)$. (B) Decreased MBF after desipramine challenge $(P<0.001)$.
$(R)-{ }^{11} \mathrm{C}$-rolipram metabolism results in radioactivity accumulating in whole blood at early time points, with more activity found in the plasma fraction at later time points (>30 min), consistent with our previous data (17). The shift in radioactivity from whole blood to plasma could be due to the appearance of labeled metabolites over time or the release of parent $(R)-{ }^{11} \mathrm{C}$-rolipram through competitive displacement by unlabeled compound.

Rapid $(R)-{ }^{11} \mathrm{C}$-rolipram metabolism in rats was observed, with about $50 \%$ of the parent compound in plasma at $5 \mathrm{~min}$ and less than $30 \%$ at $15 \mathrm{~min}$ after tracer administration. The metabolite correction derived from our high-dose metabolite studies is similar to the high-specific-activity (low-dose) data reported by Fujita et al. (4), suggesting a minimal effect of cold rolipram in the range encountered here. To our knowledge, there are no reports on the effect of desipramine on $(R)-{ }^{11} \mathrm{C}$-rolipram metabolism. Despite this potential effect, the rolipram blocking and desipramine results are in good agreement with the percentage changes reported in our previous ex vivo biodistribution studies $(10,11)$.

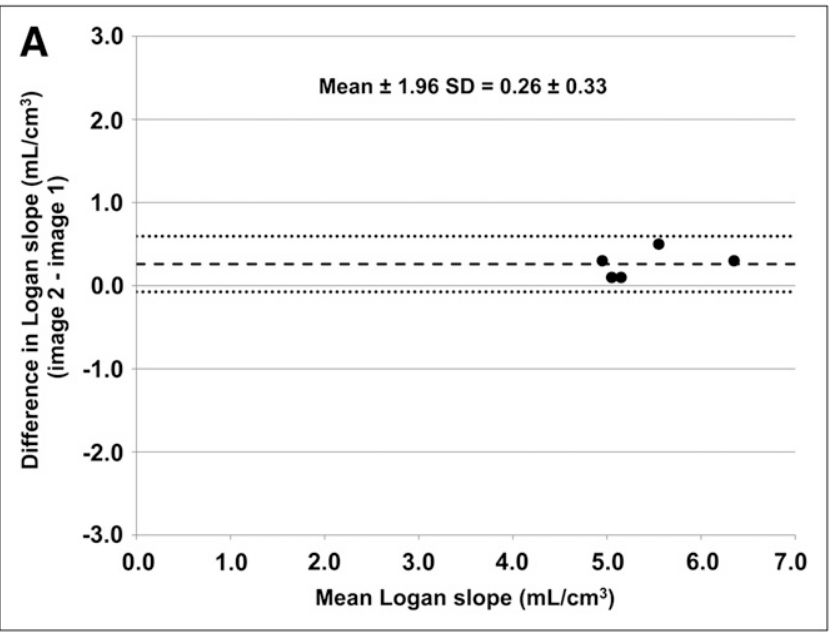

FIGURE 7. Bland-Altman plot comparing test-retest Logan slope values for $(R)-{ }^{11} \mathrm{C}$-rolipram in left ventricular rat myocardium. Mean difference between Logan slope repeated measures ( $n=5$, image 2 - image 1) was 0.26 , representing small but significant bias of $5 \%$ $(P<0.05)$. Repeatability coefficient was $0.33 \mathrm{~mL} / \mathrm{cm}^{3}$, or $6 \%$ of mean.
Small-animal PET with $(R)-{ }^{11} \mathrm{C}$-rolipram in rats revealed the greatest tracer binding to the heart, brain, and liver. High liver activity is typical of radiotracers that undergo hepatic metabolism, and it has been demonstrated that liver activity associated with $(R)-{ }^{11} \mathrm{C}$-rolipram does not represent specific binding (11). Conversely, the tracer accumulation in cardiac and brain tissues confirms previous in vivo biodistribution studies $(10,11)$ and imaging experiments (4-7), reflecting the high PDE4 levels in these tissues (18).

Enzyme saturation studies at varying injected masses $(0.00016-1.09 \mathrm{mg} / \mathrm{kg})$ revealed an inverse relationship between increasing injected mass and reduced Logan slope, consistent with greater PDE4 enzyme saturation by nonlabeled compound. This effect follows the expected shape of a sigmoid curve, indicating more than $90 \%$ saturation of the available enzyme with injected masses greater than $0.02 \mathrm{mg} / \mathrm{kg}$. This study determined an in vivo cardiac $\mathrm{ED}_{50}$ for $(R)$-rolipram of about $0.002 \mathrm{mg} / \mathrm{kg}$, compared with previous estimates of $0.03 \mathrm{mg} / \mathrm{kg}$ in rat heart (11) and $0.002 \mathrm{mg} / \mathrm{kg}$ in pig brain (8). Our estimated in vivo $\mathrm{ED}_{50}$ is approximately an order of magnitude smaller than the ex vivo-derived value reported by Kenk et al. (11) but virtually identical to that reported by Parker et al. (8).

Using Equation 1 with the $\mathrm{ED}_{50}$ presented here, we estimate the in vivo enzyme occupancy of PDE4 by unlabeled rolipram to be less than $5 \%$ at mass doses of less than $0.0001 \mathrm{mg} / \mathrm{kg}$ and less than $10 \%$ at less than $0.0002 \mathrm{mg} / \mathrm{kg}$ in the rat heart. Unfortunately, radiochemistry limitations in achievable specific activity prevented us from investigating the less than $5 \%$ occupancy that is advised in radioligand binding studies (16). To achieve these small injected masses with a typical 325-g rat, routine radiochemistry tracer synthesis would have to yield specific activities of more than 166.5 $\mathrm{GBq} / \mu \mathrm{mol}$, to also allow injected activities of 18.5 $\mathrm{MBq}$ or more that are required for high-quality PET. Therefore, a value of less than $0.0002 \mathrm{mg} / \mathrm{kg}$ was targeted for imaging in the low-occupancy $(<10 \%)$ condition. This value proved sufficient to show the presence of PDE4-specific binding in the rat heart that was reproducible and responsive to desipramine challenge.

Preadministration of a saturating dose of $(R)$-rolipram $(>1 \mathrm{mg} / \mathrm{kg})$ was sufficient to decrease $(R)-{ }^{11} \mathrm{C}$-rolipram binding to nonspecific levels, with a Logan slope of about $3.3 \mathrm{~mL} / \mathrm{cm}^{3}$; however, substantial blocking appears to occur 
with doses as low as $0.02 \mathrm{mg} / \mathrm{kg}$, or $90 \%$ occupancy. Qualitatively, this blocking results in a dramatic loss of contrast between myocardium and blood in the PET images. Quantitatively the reduction in Logan slope, compared with baseline, suggests about $40 \%$ specific binding of $(R)-{ }^{11} \mathrm{C}$ rolipram, assuming that the bias from labeled metabolites is relatively small and constant across all imaging conditions. The reduction seen here closely parallels ex vivo findings: biodistribution studies in rats showed a $30 \%$ reduction in $(R)-{ }^{11} \mathrm{C}$-rolipram LV binding when blocked with unlabeled rolipram (11), and $(R)-{ }^{11} \mathrm{C}$-rolipram specific binding in the heart at 45 min after tracer administration was $41 \%$, as determined by high-performance liquid chromatography (12).

Compared with baseline, desipramine challenge resulted in a 24\%-30\% increase in Logan slope. This follows the increase reported using ex vivo biodistribution, for which a $21 \%$ increase in $(R)-{ }^{11} \mathrm{C}$-rolipram specific binding in the heart was attributed to desipramine treatment (10). Interestingly, a 23\% reduction in MBF was observed in these studies using ${ }^{13} \mathrm{~N}$-ammonia imaging. Hemodynamic depression is noted at high doses of imiprine (19), the active metabolite of desipramine. Thus, the reduction of myocardial flow, opposite to the increase in $(R)-{ }^{11} \mathrm{C}$-rolipram uptake, provides additional evidence of the tracer's specific and directed uptake related to PDE4 levels.

Quantitatively, the low-occupancy imaging condition revealed a mean Logan slope of about $5.5 \mathrm{~mL} / \mathrm{cm}^{3}$, confirmed by test-retest studies within the same animals and in measurements of independent animals. Indeed, the reproducibility of tracer quantification was highly robust, as testretest studies within the same animal resulted in quantitative differences of less than 5\%. As expected, variability between interanimal studies at about $15 \%$ is higher than that seen in intraanimal studies. The larger difference seen in interrat studies may result from the application of population average arterial input function corrections. Indeed this observation of low intraanimal variability highlights the potential advantage of small-animal PET for repeated measures in the same animal, allowing the detection of in vivo differences more readily with smaller samples.

Itoh et al. (6) has demonstrated that isoflurane anesthesia reduces $(R)-{ }^{11} \mathrm{C}$-rolipram brain uptake in rats, and a possible analogous effect on the heart should be explored to ensure reliable interpretation of the data. Future work should aim to correlate in vivo cardiac $(R)-{ }^{11} \mathrm{C}$-rolipram binding with in vitro measures of PDE4 expression or activity. Differences in sympathetic nervous system signaling, tracer binding and metabolism will need to be evaluated in translating these results from rats to other species. The application of $(R)-{ }^{11} \mathrm{C}$-rolipram in animal models of disease may also help facilitate the translation of this radiotracer to clinical practice. In particular, cardiac pathologies that are either the cause or a consequence of elevated sympathetic nervous system tone are potential imaging targets. Heart failure is a prime example, in which chronic sympathetic nervous system stimulation alters the $\beta$-adrenergic receptor function. Given the pivotal importance of cAMP in regulating ventricular contractile function, an index of cAMP levels could help to ultimately guide therapeutic approaches on an individual basis or to evaluate the effects of new therapies in heart failure.

\section{CONCLUSION}

$(R)-{ }^{11} \mathrm{C}$-rolipram small-animal PET demonstrates PDE4 binding in the rat heart, which is sensitive to changes in PDE4 levels. Quantification of the tracer distribution volume by Logan graphical analysis is reproducible and minimally affected by operator and test-retest variability. $(R)-{ }^{11} \mathrm{C}$-rolipram with small-animal PET has the ability to evaluate cardiac intracellular cAMP-mediated PDE4 signaling in an in vivo setting.

\section{ACKNOWLEDGMENTS}

We acknowledge the radiochemistry staff (Samantha Mason, Paul Coletta, and Jeffrey Collins) for tracer production and animal care and the veterinary staff (Stephanie Thorn, Myra Kordos and Julia Lockwood) for assistance with PET. This study was supported by Canadian Institutes of Health Research grant FRN78520, Heart and Stroke Foundation of Ontario grant NA6477, Molecular Function and Imaging program grant PRG6242, and the Heart and Stroke Foundation of Ontario.

\section{REFERENCES}

1. Osadchii OE. Myocardial phosphodiesterases and regulation of cardiac contractility in health and cardiac disease. Cardiovasc Drugs Ther. 2007;21:171-194.

2. Schneider HH, Schmiechen R, Brezinski M, Seidler J. Stereospecific binding of the antidepressant rolipram to brain protein structures. Eur J Pharmacol. 1986; 127:105-115.

3. DaSilva JN, Lourenco CM, Wilson AA, Houle S. Syntheses of the phosphodiesterase-4 inhibitors $\left[{ }^{11} \mathrm{C}\right] \mathrm{Ro} 20-1724, \mathrm{R}-\mathrm{R} / \mathrm{S}$ and S- $\left[{ }^{11} \mathrm{C}\right]$ rolipram. J Labeled Comp Radiopharm. 2001;44:373-384.

4. Fujita M, Zoghbi SS, Crescenzo MS, et al. Quantification of brain phosphodiesterase 4 in rat with (R)-[ $\left.{ }^{11} \mathrm{C}\right]$ Rolipram-PET. Neuroimage. 2005;26:1201-1210.

5. Fujita M, Imaizumi M, D'Sa C, et al. In vivo and in vitro measurement of brain phosphodiesterase 4 in rats after antidepressant administration. Synapse. 2007; 61:78-86.

6. Itoh T, Abe K, Zoghbi SS, et al. PET measurement of the in vivo affinity of ${ }^{11} \mathrm{C}$ $(R)$-rolipram and the density of its target, phosphodiesterase-4, in the brains of conscious and anesthetized rats. J Nucl Med. 2009;50:749-756.

7. Itoh T, Abe K, Hong J, et al. Effects of cAMP-dependent protein kinase activator and inhibitor on in vivo rolipram binding to phosphodiesterase 4 in conscious rats. Synapse. 2010;64:172-176.

8. Parker CA, Matthews JC, Gunn RN, et al. Behaviour of $\left[{ }^{11} \mathrm{C}\right] \mathrm{R}(-)-$ and $\left[{ }^{11} \mathrm{C}\right] \mathrm{S}(+)$-rolipram in vitro and in vivo, and their use as PET radiotracers for the quantificative assay of PDE4. Synapse. 2005;55:270-279.

9. DaSilva JN, Lourenco CM, Meyer JH, Hussey D, Potter WZ, Houle S. Imaging cAMP-specific phosphodiesterase-4 in human brain with R- $\left[{ }^{11} \mathrm{C}\right]$ rolipram and positron emission tomography. Eur J Nucl Med Mol Imaging. 2002;29:16801683 .

10. Lourenco CM, Kenk M, Beanlands RS, DaSilva JN. Increasing synaptic noradrenaline, serotonin and histamine enhances in vivo binding of phosphodiesterase-4 inhibitor (R)-[ $\left[{ }^{11} \mathrm{C}\right]$ rolipram in rat brain, lung and heart. Life Sci. 2006;79:356-364.

11. Kenk M, Greene M, Thackeray J, et al. In vivo selective binding of (R)- $\left[{ }^{11} \mathrm{C}\right]$ rolipram to phosphodiesterase- 4 provides the basis for studying intracellular cAMP signaling in the myocardium and other peripheral tissues. Nucl Med Biol. 2007;34:71-77.

12. Kenk M, Greene M, Lortie M, Dekemp RA, Beanlands RS, Dasilva JN. Use of a column-switching high-performance liquid chromatography method to assess the 
presence of specific binding of (R)- and (S)-[(11)C]rolipram and their labeled metabolites to the phosphodiesterase-4 enzyme in rat plasma and tissues. $\mathrm{Nucl}$ Med Biol. 2008;35:515-521.

13. Valdivia AC, Mason S, Collins J, et al. Radiosynthesis of N-[(11)C]-methylhydroxyfasudil as a new potential PET radiotracer for rho-kinases (ROCKs). Appl Radiat Isot. 2010;68:325-328.

14. DeGrado TR, Hanson MW, Turkington TG, et al. Estimation of myocardial blood flow for longitudinal studies with ${ }^{13} \mathrm{~N}$-labeled ammonia and positron emission tomography. J Nucl Cardiol. 1996;3:494-507.

15. Logan J, Fowler JS, Volkow ND, Wang GJ, Ding YS, Alexoff DL. Distribution volume ratios without blood sampling from graphical analysis of PET data. $J$ Cereb Blood Flow Metab. 1996;16:834-840.
16. Hume SP, Gunn RN, Jones T. Pharmacological constraints associated with positron emission tomographic scanning of small laboratory animals. Eur J Nucl Med. 1998;25:173-176.

17. Lourenco CM, Houle S, Wilson AA, DaSilva JN. Characterization of R- $\left[{ }^{11} \mathrm{C}\right]$ rolipram for PET imaging of phosphodieterase-4: in vivo binding, metabolism, and dosimetry studies in rats. Nucl Med Biol. 2001;28:347-358.

18. Maurice DH, Palmer D, Tilley DG, et al. Cyclic nucleotide phosphodiesterase activity, expression, and targeting in cells of the cardiovascular system. $\mathrm{Mol}$ Pharmacol. 2003;64:533-546.

19. Langslet A, Johansen WG, Ryg M, Skomedal T, Oye I. Effects of dibenzepine and imipramine on the isolated rat heart. Eur J Pharmacol. 1971; 14:333-339. 